\title{
Full length genome sequence of Polish isolate of Beet soil-borne virus confirms low level of genetic diversity
}

\author{
Natasza Borodynko $\bowtie$, Beata Hasiów-Jaroszewska, Natalia Rymelska \\ and Henryk Pospieszny \\ Institute of Plant Protection - National Research Institute, Department of Virology and Bacteriology, \\ Poznań, Poland
}

Received: 25 June, 2009; 19 November, 2009; accepted: 09 December, 2009

available on-line: 09 December, 2009

\begin{abstract}
The complete nucleotide sequence of a Polish isolate of Beet soil-borne virus was determined for the first time. The genome organization was identical with those previously established for isolates from Germany and China. A comparison of the Polish isolate with others deposited in GenBank reveled high level of nucleotide identity, about $98-100 \%$, throughout the genome analyzed. The ratio between non-synonymous and synonymous substitutions was rather low suggesting a negative selective pressure. The non-synonymous mutations were particulary frequent in triple gene block.
\end{abstract}

Keywords: BSBV, genetic diversity, Polymyxa betae

\section{INTRODUCTION}

Beet soil-borne virus (BSBV) is a poorly characterized rod-shaped virus of sugar beet originally described by Ivanović and Macfarlane (1982). First detect in the United Kingdom, BSBV was then reported in many European countries as well as the United States (Meunier et al., 2003). In the Middle East, BSBV was described in Iran (Farzadfar et al., 2002) and Syria (Mouhanna et al., 2002). In 2006 BSBV was reported for the first time in Poland (Borodynko et al., 2006). At the same time the virus was found in China (Wang et al., 2007). BSBV has a tripartite genome consisting of three positive-sense RNA molecules.

The virus has a narrow host range restricted to Beta vulgaris and is transmitted by Polymyxa betae. Many other soil-borne viruses are known to infect sugar beet (B. vulgaris L. ssp. vulgaris) worldwide, such as Beet necrotic yellow vein virus (BNYVV) and Beet virus $Q(B V Q)$. It has been shown previously that BSBV, BVQ and BNYVV are widespread in Po- land and often occur in mixed infection (Mazowsze, Dolny Śląsk) (Borodynko \& Pospieszny, 2007). The Polish BSBV isolate described in this paper was obtained from a sugar beet plant from the Wielkopolska region where the virus occurred separately. A low level of genetic diversity among the Polish isolates of BNYVV, BSBV and BVQ viruses was before noticed (Borodynko et al., 2009). Although BSBV is spread worldwide, the information on its complete genome sequence and genetic diversity is limited. So far, only the complete sequences of a German isolate (BSBV-G) and two Chinese (BSBV-XJ and BSBV-IM) isolates have been determined (Koenig et al., 1996; 1997; Koenig \& Loss, 1997; Wang et al., 2008).

Studies of the genetic structure and diversity of viruses are of a practical interest in the development of strategies for the control of viral diseases. In the case of RNA plant viruses, knowledge of their genetic diversity is important for efforts to breed for host resistance.

Here, we report the complete nucleotide sequence of the first Polish BSBV isolate and a se-

Corresponding author: Natasza Borodynko, Institute of Plant Protection - National Research Institute, Department of Virology and Bacteriology, Węgorka 20, 60-318 Poznań, Poland; phone: (48) 61864 9093; fax: (48) 61 867 6301; e-mail: N.Borodynko@ior.poznan.pl

Abbreviations: BNYVV, Beet necrotic yellow vein virus; BSBV, Beet soil-borne virus; BVQ, Beet virus Q; nt, nucleotides; RT$\mathrm{PCR}$, reverse transcriptase-polymerase chain reaction; PCR, polymerase chain reaction; TGB, triple gene block; UTR, untranslated region. 
quence analysis indicating low level of genetic diversity.

\section{MATERIALS AND METHODS}

Total plant RNA was obtained from sugar beet roots ground in liquid nitrogen and then extracted with hot phenol/chloroform. This approach allows us to obtained a total RNA concentration of about $3 \mu \mathrm{g} / \mu \mathrm{l}$. Overlapping RT-PCR products covering all of RNAs 1, 2 and 3 were obtained with own primer pairs designed on the basis of the previously published sequence of a German BSBV-G isolate. We were not able to obtain any PCR products with primers described previously for the BSBV-G isolate. For determining the $5^{\prime}$ terminal sequences of RNAs the 5' RACE system was used (Invitrogen). The PCR fragments were purified from agarose gel and cloned into the pGEM-T Easy vector or sequenced directly. The complete sequence was established using BioEdit program (Hall, 1999) and deposited in the GenBank database under accession numbers: FJ971717-FJ971719. Confidence estimates for non-synonymous (amino-acid-replacing) (dNS) and synonymous (silent mutational) (dS) nucleotide substitutions were calculated by using the bootstrap method with 1000 replicates.

\section{RESULTS AND DISCUSSION}

The complete sequence of RNA 1, 2 and 3 of BSBV-PL consisted of 5834, 3454 and 3005 nt respectively. The genome organization was identical to that of BSBV-G, BSBV-IM, and BSBV-XJ. The problems with obtaining PCR products with primers described previously suggested some genetic diversity between the BSBV isolates, however, the subsequent comparison did not confirm it.

The comparison of the Polish BSBV genome sequence to the German and Chinese isolates reveled $98.1-98.8 \%$ for RNA 1, 98.4-98.5\% for RNA 2 and $97.1-97.8 \%$ for RNA 3 identity at the nucleotide level, and 98.8-99.3\% (RNA 1), 98-98.2\% (RNA 2) and about $97 \%$ (RNA 3) identity at the amino acid level. The most conserved second gene of the triple gene block of BSBV-PL shared 97.4-98.2\% sequence identity with other BSBV isolates, where BSBV-XJ and BSBV-IM showed 100\% amino-acid sequence identity. The comparisons showed that BSBV-PL is more similar to the two Chinese isolates then to BSBV-G. RNA 1 and RNA 2 of all BSBV isolates were rather conserved although we noticed some non-synonymous mutations, mostly, preserving the chemical properties of encoded amino acids. However, in RNA 1 of BSBV-G we found substitutions in comparison with BSBV-PL, BSBV-IM and BSBV$\mathrm{XJ}$ sequences resulting in very rare amino acid changes: serine in BSBV-G to cysteine in others or tryptophan to glycine. We suppose these differences could be due to sequencing mistakes. The most variable was RNA 3. In the N-terminal part of TGB1 protein we noticed a few amino acids changes, TGB2 and TGB3 were more conserved. Highly variable was also the $3^{\prime}$ end of RNA 3. The nucleotide sequences corresponding to putative BSBV coding regions were aligned and used to estimate genetic distances between each pair of isolates. Values of genetic distances at synonymous positions between pairs of isolates for all RNA 1 and RNA 2 coding regions ranged from 0 to 0.049 . Higher values were only obtained for RNA 3. Sequence analysis confirmed that all BSBV isolates identified to date are closely related to each other and considerably conserved especially in the case of RNA 1 and RNA 2. We can identify some regions in BSBV RNA 3 which are more variable, like the $5^{\prime}$ end of TGB1 and the $3^{\prime}$ end of RNA including part of TGB3 gene and $3^{\prime}$ UTR. Understanding of the distribution of genetic diversity among individuals, populations and gene pools is crucial for efficient management of germplasm collections and breeding programs. Although many environmental factors can exert evolutionary constraints on viruses, the host plant is believed to be one of the most important. The limited host range may be related to the levels of diversity. It has been shown before that genetic diversity of RNA viruses is controlled by host-virus interactions and the quasispecies cloud size remains constant as long as the virus is maintained on a given host (Schneider \& Roossinck, 2001). In Spain, the whitefly-transmitted Cucumber vein yellowing virus infects cucumber crops that generally overlap throughout the whole year, providing stable ecological conditions for the virus, vector, and host plant interaction as the predominant selection pressure that may contribute to genetic stability (Janssen et al., 2007).

Genetic bottlenecks are evolutionary events that reduce genetic variation of a population and may occur at different points during the life cycle of plant RNA viruses. Recently, genetic bottlenecks have been shown experimentally in a plant virus population during systemic movement within the plant and horizontal transmission from plant to plant by vectors (French \& Stenger, 2003; Ali et al., 2006). Similarly, one may expect that the transmission of BSBV by $P$. betae can impose a bottleneck and reduce the genetic variation of the virus population.

The overall variability observed in BSBV worldwide suggests high genetic stability that could be explained, at least in part, by the ecological bottleneck in which host plants and vectors are continuously maintained. 


\section{Acknowledgements}

Research supported by grant N31001731 from the Ministry of Science and Higher Education.

\section{REFERENCES}

Ali A, Schneider WL, Sherman DJ, Gray S, Smith D, Roosinck MJ (2006) Analysis of genetic bottlenecks during horizontal transmission of cucumber mosaic virus. J Virol 80: 8345-8350.

Borodynko N, Pospieszny H (2007) Identyfikacja i występowanie odglebowych wirusów buraka cukrowego w Polsce. Prog Plant Prot 47: 55-61 (in Polish).

Borodynko N, Hasiów B, Pospieszny H (2006) First Report of Beet soilborne virus in Poland. Plant Dis 90: 112.

Borodynko N, Rymelska N, Hasiów-Jaroszewska B, Pospieszny H (2009) Molecular characterization of three soil-borne sugar beet-infecting viruses based on the coat protein gene. J Plant Pathol 91: 189-191.

Farzadfar SH, Pourrahim R, Golnaraghi AR, Shahraeen N (2002) First report of Beet soil-borne virus on sugar beet in Iran. Plant Dis 86: 187.

French R, Stenger DC (2003) Evolution of Wheat streak mosaic virus: dynamics of population growth within plants may explain limited variation. Annu Rev Phytopathol 41: 199-214.

Hall TA (1999) BioEdit: a user-friendly biological sequence alignment editor and analysis program for Windows 95/98/NT. Nucleic Acids Symp Ser 41: 95-98.

Ivanović M, Macfarlane I (1982) A tubular virus associated with infection of sugar beet by Polymyxa betae. Report of Rothamsted Experimental Station for 1981, pp 190191.

Janssen D, Velasco L, Martin G, Segundo E, Cuadrado IM (2007) Low genetic diversity among Cucumber vein yel- lowing virus isolates from Spain. Virus Genes 34: 367371.

Koenig R, Loss S (1997) Beet soil-borne virus RNA1: genetic analysis enabled by a starting sequence generated with primers to highly conserved helicase-encoding domains. J Gen Virol 78: 3161-3165.

Koenig R, Beier C, Commandeur U, Luth U, Kaufmann A, Luddecke P (1996) Beet soil-borne virus RNA 3 - a further example for the heterogeneity of the gene content of furovirus genomes and of triple gene block-carrying RNAs. Virology 216: 202-207.

Koenig R, Commandeur U, Loss S, Beier C, Kaufmann A, Lesemann DE (1997) Beet soil-borne virus RNA 2: similarities and dissimilarities to the coat protein gene-carrying RNAs of other furoviruses. J Gen Virol 78: 469477.

Meunier A, Schmit JF, Stas A, Kutluk N, Bragard C (2003) Multiplex reverse transcription-PCR for simultaneous detection of Beet necrotic yellow vein virus, beet soilborne virus, and Beet virus $Q$ and their vector Polymyxa betae Keskin on sugar beet. Appl Environ Microb 69: 23562360.

Mouhanna AM, Nasrallah A, Langen G, Schlösser E (2002) Surveys for Beet Necrotic Yellow Vein Virus (the cause of Rhizomania), other viruses, and soil-borne fungi infecting sugar beet in Syria. J Phytopathol 150: 657-662.

Schneider WL, Roossinck MJ (2001) Genetic diversity in RNA virus quasispecies is controlled by host-virus interactions. J Virol 75: 6566-6571.

Wang B, Li M, Zhang JJ, Han CG, Li DW, Yu JL (2007) First report of Beet soil-borne virus on sugar beet in China. Plant Pathol 57: 389.

Wang B, Li M, Han C, Li D, Yu JL (2008) Complete genome sequence of two Chinese Beet soil-borne virus isolates provide evidence that the genome is highly conserved. J Phytopathol 156: 487-488. 